Report No. BMI-1432

UC-37 Instrumentation

(TID-4500, 15th Ed.)

Contract No. W-7405-eng-92

DEVELOPMENT OF A IEL-ELEMENT LEAK-DETECTION

SYSTEM BASED ON THE PRINCIPLE

OF ISOTOPIC EXCHANGE

by

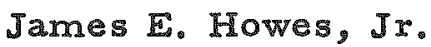

Thomas S. Elleman

Duane N. Sunderman

August 1, 1960

BATTELLE MEMORIAL INSTITUTE

$505 \mathrm{King}$ Avenue

Columbus 1, Ohio 


\section{DISCLAIMER}

This report was prepared as an account of work sponsored by an agency of the United States Government. Neither the United States Government nor any agency Thereof, nor any of their employees, makes any warranty, express or implied, or assumes any legal liability or responsibility for the accuracy, completeness, or usefulness of any information, apparatus, product, or process disclosed, or represents that its use would not infringe privately owned rights. Reference herein to any specific commercial product, process, or service by trade name, trademark, manufacturer, or otherwise does not necessarily constitute or imply its endorsement, recommendation, or favoring by the United States Government or any agency thereof. The views and opinions of authors expressed herein do not necessarily state or reflect those of the United States Government or any agency thereof. 


\section{DISCLAIMER}

Portions of this document may be illegible in electronic image products. Images are produced from the best available original document. 
Equipment and Reagents . . . . . . . . . . . . . . . . . 3

Rate of Dissolution of Silver Chloride, Silver Bromide, and Silver Iodide. . . . . . . . . . . . . . . . . . . 6

Fixchange Between Silver Bromide and Iodine-131 and Bromine-82

Rate of Removal of Bromine-82 and Iodine-131 From

Silver Bromide Columns . . . . . . . . . . . . . . . . . 10

Fission-Product-Decontamination Studies . . . . . . . . . . . . 10

Calculation of Halide Buildup on Silver Bromide Columns . . . . . . 13

DISCUSSION AND CONCLUSIONS . . . . . . . . . . . . . . . . . . 14

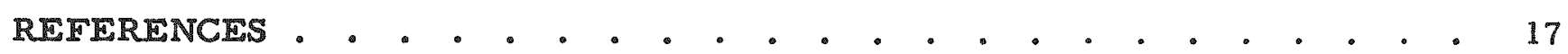




\title{
DEVELOPMENT OF A FUEL-ELEMENT LEAK-DETECTION SYSTEM BASED ON THE PRINCIPLE OF ISOTOPIC EXCHANGE
}

\author{
James F. Howes, Jr., Thomas S. Elleman, and Duane N. Sunderman
}

\begin{abstract}
The selective removal of halide fission products from an aquecus solution by excharge with the halide in solid silver halide has been studied as the basis for a fuel-element leak detector. The retention of fission-product halides on a silver halide column was investigated as a fanction of coolant fow rate, halide anion, and column size. Fission product decontamination factors and predicted operating lifetimes were obtained for a number of reactor operating conditions.
\end{abstract}

16 was comcluded that sensitive, rapid leal detector for water-cooled reacior could be constructed from a silver bromide or iodide column monitored by a neutron detector to detect deloyed neatrons from the halide fission products. The feasibility of gross gamma monitoring is dependent upon the intensity of the gamma bacleground arising from absorbed fission products on the silver halide column. The equilibrium value of this background can be determined only through in-pile experiments.

\section{INTRODUCTION}

When a reactor fuel element ruptures, radioactive fission products are generally released to the reactor coolant. This fission-product release can result in undesirable contamination of the entire coolant system and present a radiation hazard to personnel working in the area. It is therefore desirable that reactors contain some type of fuelelement leak detector which gives advanced warning of a fuel-element rupture before the spread of fission products becomes extensive. This report describes the development of a fuel-element leak-detection system based on the removal of fission-product halides from the coolant by halide exchange with a solid silver halide. The work has been carried out under the sponsorship of Hanford Atomic Products Operation. The scope of the program has been to evaluate the factors involved in the utilization of a silver halide leak detector and to construct a prototype model for further evaluation on a reactor loop.

The discovery of a fuel-element failure is generally based on the detection of one or more fission products in the reactor coolant following a failure. In a typical leakdetection system, a volume of the coolant or some constituent in the coolant is isolated and the radioactivity is measured to determine if failure has occurred. Among the systems which have been proposed are those which measure gross gamma activity $(1,2) \%$, delayed neutrons $(1,3)$, or high-energy beta particles $(4)$ in an isolated volume of the coolant. These systems generally have poor sensitivity when used in water-cooled reactors since activation of the coolant and corrosion products yields a high counting background. The background may be lowered by permitting the short-lived coolant radioisotopes to decay before radioassay of the coolant, but this technique undesirably delays the detection of a fuel-element rupture.

- References at the end. 
Ion-exchange resins have been used to concentrate cationic or anionic fission products in the coolant and thus increase the signal-to-background ratio for the detection of a fuel-element leak. In one system of this type (5) the anion-exchange column was monitored with a gamma probe which was biased to measure only those gamma rays with energies in the range from 0.8 to $4.0 \mathrm{Mev}$. In the instance of a fuel-element failure, iodine and bromine fission products separated by the anion column indicated that a failure had occurred. This system is reported to be sensitive but requires frequent replacement of the resins.

Centrifuging of particulate matter and temperature and flow monitoring are other techniques which have been used with varying success for the determination of fuelelement rupture. Unfortunately, none of the procedures mentioned possesses all of the desired attributes of high sensitivity, rapid response, simplicity, and dependability.

The system presently under investigation is based upon the removal of fissionproduct halides from the coolant by exchange with solid silver halide.

The exchange process may be represented by the equation:

$$
\mathrm{AgX}_{\text {(solid) }}+\mathrm{X}^{*} \text { (solution) } \overrightarrow{\mathrm{AgX} *} \text { (solid) }+\mathrm{X}_{\text {(solution) }}
$$

The leak-detection system consists of a column of solid silver halide (iodide or bromide) through which a fraction of the coolant is passed. The halide fission products are selectively separated and concentrated by the isotopic-exchange reaction. A leak is detected by monitoring the silver halide column with a radiation detector. A rapid rise in radiation level on the column indicates a leak.

The behavior of halide fission products in an aqueous system favors their use for the indication of a fuel-element failure. It has been found $(6,7)$ that nearly all fissionproduct halides remain in solution whereas other fission products may be retained on the walls of the coolant system. Also, the halides emit delayed neutrons, thus affording the possibility of either gross-gamma or delayed-neutron monitoring.

Earlier investigations of halide exchange at Battelle have indicated the feasibility of this system for detecting a fuel-element failure. (8) The work described in this report was conducted with the objective of further investigating the system and constructing a prototype detector.

\section{EXPERIMENTAL WORK AND RESULTS}

The experimental program included the following areas of investigation: (1) determination of the rate of dissolution of $\mathrm{AgCl}, \mathrm{AgBr}$, and $\mathrm{AgI}$ at $180 \mathrm{~F}$ under coolant-flow conditions, (2) determination of the effects of flow rate, column size, and temperature on the halide exchange between AgBr and iodine-131 and bromine-82, (3) determination of the gross fission-product retention by $\mathrm{AgBr}$ and (4) investigation of possible techniques for reducing the fission-product retention. 
Equipment and Reagents

The equipment used in the program is described below:

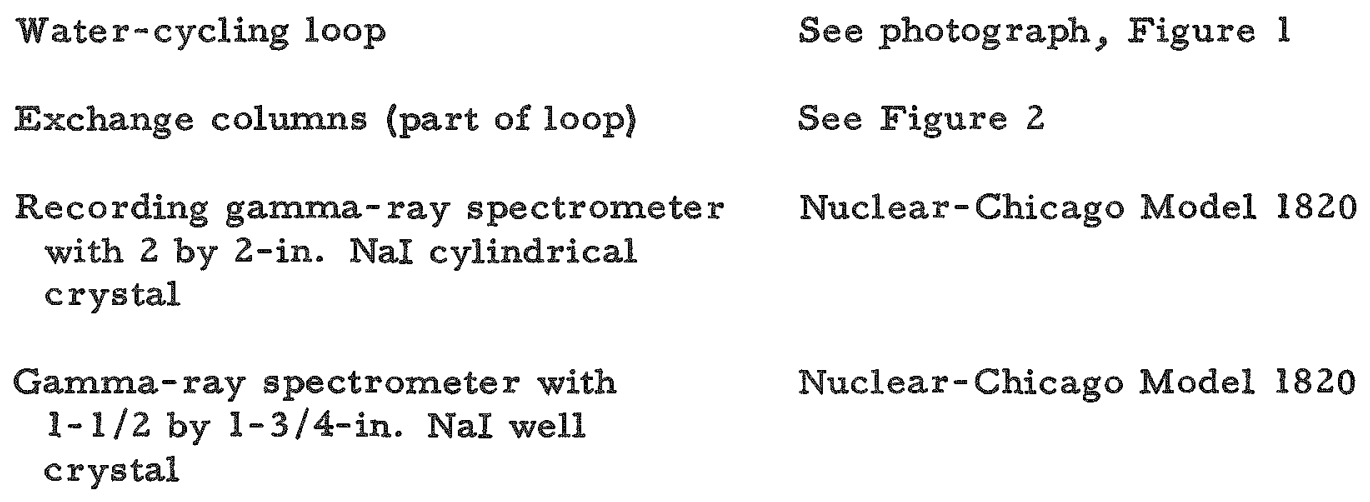

The water-cycling loop was constructed to study rate of dissolution, exchange, and fission-product decontamination under flow and temperature conditions which would be encountered in actual operation of a leak-detection system.

The following reagents were used in performing the experiments:

Fused silver bromide, minus 16 plus $50 \mathrm{mesh}$
Fused silver iodide, minus 16 plus 50 mesh
Silver-110-tagged silver bromide, fused
Silver-110-tagged silver iodide, fused

Radioactive tracer solutions
Reagent silver bromide (Fisher Chem- ical No. S-172) was fused for $1 \mathrm{hr}$ at $445 \mathrm{C}$, then pulverized under liquid nitrogen and screened for the minus 16 plus $50-$ mesh fraction

Reagent silver iodide (Fisher Chemical No. S-178) was fused for $1 \mathrm{hr}$ at $565 \mathrm{C}$ and treated as above

Sodium bromide was reacted with silver-110-tagged silver nitrate, and the material was fused, pulverized, and screened to obtain minus 16 plus 20-mesh fraction

Sodium iodide was reacted with silver-110-tagged silver nitrate, and the material was fused, pulverized, and screened to obtain minus 16 plus 50-mesh fraction

Listed in Table 1

Silver halides in the minus 16 plus 50 -mesh particle range were selected for use in this study since previous experience $(8)$ indicated that columns of this material size give the maximum exchange and fission-product decontamination with a minimum pressure drop. 


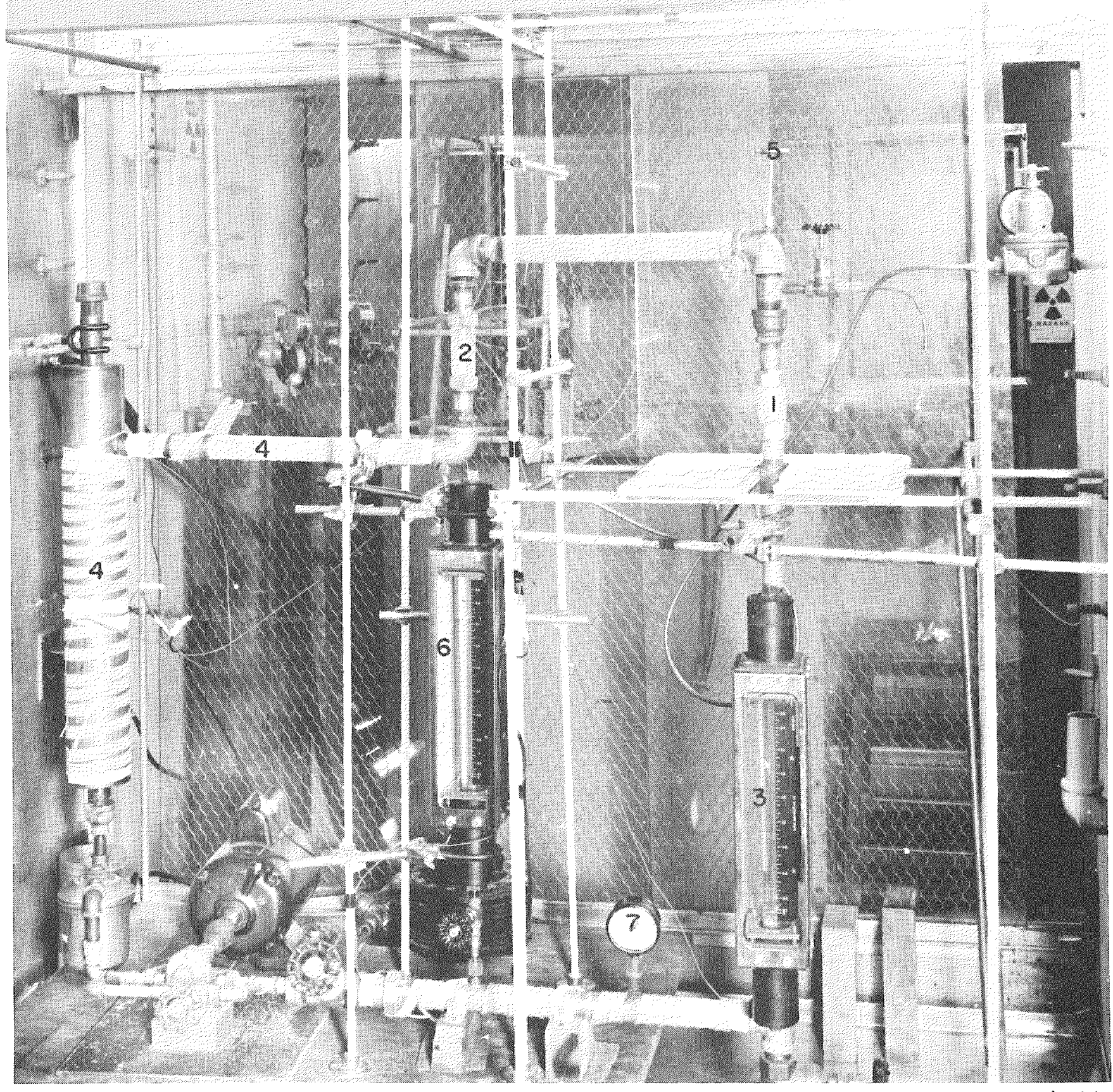

N62458

FIGURE 1. WATER RECYCLING LOOP USED IN EXPERIMENTS

1. Silver halide exchange column

2. Ion-exchange resin column

3. Flowmeter

4. Heating tape
5. The rmometer

6. Apparatus for introduction of tracers into system

7. Pressure gage 


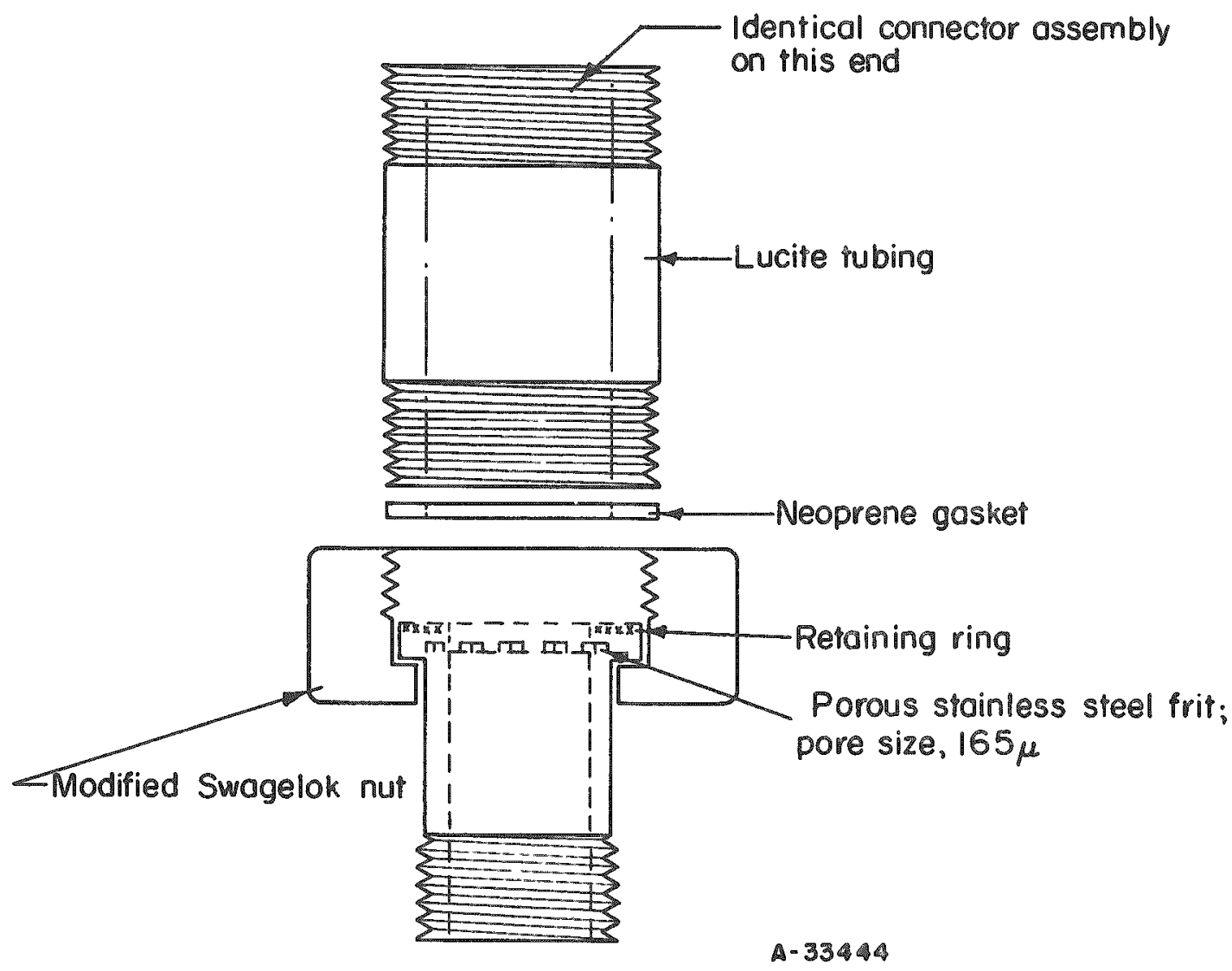

FIGURE 2. DETAIL OF ISOTOPIC EXCHANGE COLUMNS 
TABLE 1. NUCLEAR AND CHEMICAL PROPERTIES OF TRACER SOLUTIONS

\begin{tabular}{|c|c|c|c|}
\hline Isotope (a) & Chemical Form & Half-Life & Nuclear Radiations \\
\hline Iodine-131(b) & $\mathrm{NaI}$ in $\mathrm{NaOH}-\mathrm{Na}_{2} \mathrm{SO}_{3}, \mathrm{pH} 10$ & 8.05 days & $\begin{array}{l}\beta-, 0.25,0.33,0.608 \\
\text { and } 0.815 \mathrm{Mev} \\
\gamma-, 0.08,0.163,0.284 \\
0.364,0.637, \text { and } \\
0.722 \mathrm{Mev}\end{array}$ \\
\hline Bromine $-82(c)$ & $\mathrm{Kbr}$ in $\mathrm{H}_{2} \mathrm{O}$ & $35.9 \mathrm{hr}$ & $\begin{array}{l}\beta-, 0.465 \\
\gamma-, 0.547,0.766,0.823 \\
1.03, \text { and } 1.31 \mathrm{Mev}\end{array}$ \\
\hline $\begin{array}{l}\text { Gross fission } \\
\text { products }(d)\end{array}$ & & $\begin{array}{l}\text { Approximately } \\
90 \text { days old }\end{array}$ & \\
\hline
\end{tabular}

(a) Iodine and bromine isotopes were purchased from Oak Ridge National Laboratory.

(b) Carrier free.

(c) High specific activity.

(d) Irradiated uranium metal dissolved in $\mathrm{HNO}_{3}$. Fission products in essentially neutral solution when used in experiments.

$\frac{\text { Rate of Dissolution of Silver Chloride, Silver }}{\text { Bromide, and Silver Iodide }}$

The rate of dissolution of $\mathrm{AgBr}$ and $\mathrm{AgI}$ in water at $180 \mathrm{~F}$ was studied as a function of flow rate. In these experiments, water at $180 \mathrm{~F}$ was cycled through $50-\mathrm{g}(1 \mathrm{in}$. high by $1 \mathrm{in.}$. in diametex) columns of minus 16 plus 50 -mesh fused silver-110-tagged silver bromide and silver iodide. The dissolved silver from the silver-110-tagged silver halide was separated from the water by a column of cation-exchange resin. The ion-exchange column was continuously monitored with a gamma scintillation probe to determine the rate of buildup of silver-110 on the resin column. At the end of the run, the total quantity of silver halide dissolved was determined by comparing the silver-110 activity on the ionexchange resin with the activity of a known amount of silver-110-tagged silver halide. The rate of dissolution was determined from the curve obtained by monitoring the resin column and the knowledge of the total amount of silver halide dissolved.

The results of the dissolution experiments are given in Figure 3. It was observed that the rate of dissolution of silver bromide increased with flow rate, while the rate of dissolution of silver iodide increased only slightly with increasing flow rate. The reason for the differing behavior of silver iodide and silver bromide is not understood. It was initially suspected that the dissolution of silver iodide was retarded by the buildup of iodide ions in the loop from dissolved silver iodide. Since the amount of silver-110 detected on the cation resin after $1 / 2 \mathrm{hr}$ was quite low, it was not possible to monitor the rate of silver iodide dissolution to determine if it was constant with time. Several additional experiments were therefore conducted in which both cation- and anion-exchange resins were inserted in the column to remove both silver and iodide ions. The purpose of 
these experiments was to determine the true dissolution rate of silver iodide when no iodide ions were present in the coolant stream. Unfortunately, contaminating fission products desorbed from the walls of the loop raised the activity level on the exchange resins, and, since the activity values involved were quite low, it was not possible to accurately distirguish silver-110 from gross fission-product activity. However, the silver iodide dissolution rates - obtained by as suming that all the cation radioactivity derived from silver-100 - were in all cases within a factor of two of the earlier dissolution results. Thus the earlier silver iodide dissolution results appear correct.

The rate of dissolution of silver chloride was determined to be $558 \mathrm{mg}$ per hr at a flow rate of 1 gal per min. This dissolution rate is higher than can be tolerated in column operation so solubility runs were not made at other flow rates. Figure 4 shows the anticipated usable lifetime of $50 \mathrm{-g}$ minus 16 plus 50 -mesh silver bromide and silver iodide columns. These curves were calculated by assuming that solubility is the only limit on the column lifetime and that the limiting particle size is 100 mesh.

Exchange Between Silver Bromide and Iodine-131 and Bromine-82

The extent of exchange between minus 16 plus 50 -mesh fused silver bromide and iodine -131 and silver bromide and bromine-82 at $180 \mathrm{~F}$ was studied as a function of flow rate ard column size. The experiments were conducted by introducing $5-\mu \mathrm{c}$ aliquots of carrie:-free jodine -131 and bromine-82 into a stream of water flowing through the column of silver bromide. These experiments were carried out in the $100 \mathrm{p}$, and the tracers were added over a 1 -min period. The unexchanged iodine-131 or bromine-82 was separated from the water stream by an anion-exchange column. The exchange resin was inserted to prevent the iodine or bromine from being cycled through the silver bromide column a second time. The amount of iodine -131 or bromine -82 retained was determined by drying and radioassaying the AgBr. The percentage exchange was calculated by dividing the amount of iodine-131 or bromine-82 retained by the AgBr by the total quantity of trace $x$ passed through the silver bromide column.

The results of the exchange experiments are given in Figures 5 and 6 . The AgBrbromine-82 exchange and the AgBr-iodine-131 exchange varied only slightly with columnsize and flow-rate changes.

The exchange between siver bromide and bromine-82 at 180 F removed only 14 per cent of the bromine-82. However, 45 per cent of the bromine- 82 was removed from the solution at $75 \mathrm{~F}$. Apparently, the low percentage removal of bromine-82 at $180 \mathrm{~F}$ is a result of the moderate solubility of $\mathrm{AgBr}$ at this temperature which results in continuous renewal of the surface of the AgBr particles. This hypothesis is supported by the observation that bromine -82 may be readily washed off an AgBr column by flowing $180 \mathrm{~F}$ water. 


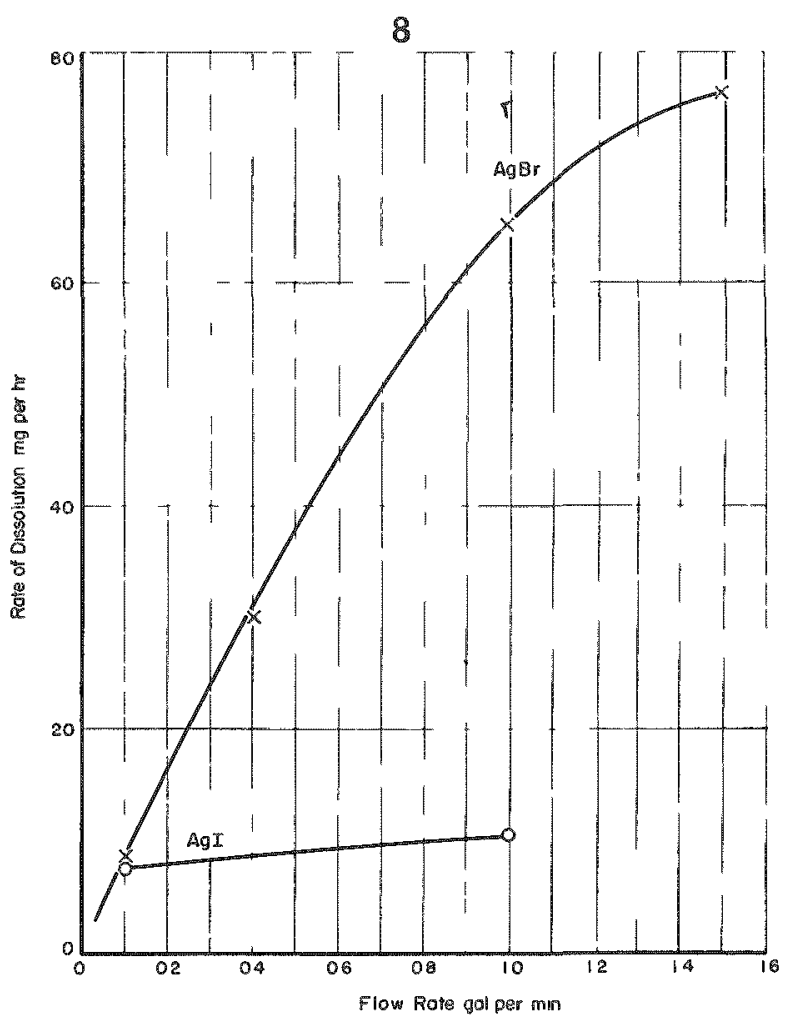

FIGURE 3. RATE OF DISSOLUTION IN 180 F WATER OF SILVER BROMIDE AND IODIDE AS A FUNCTION OF FLOW RATE

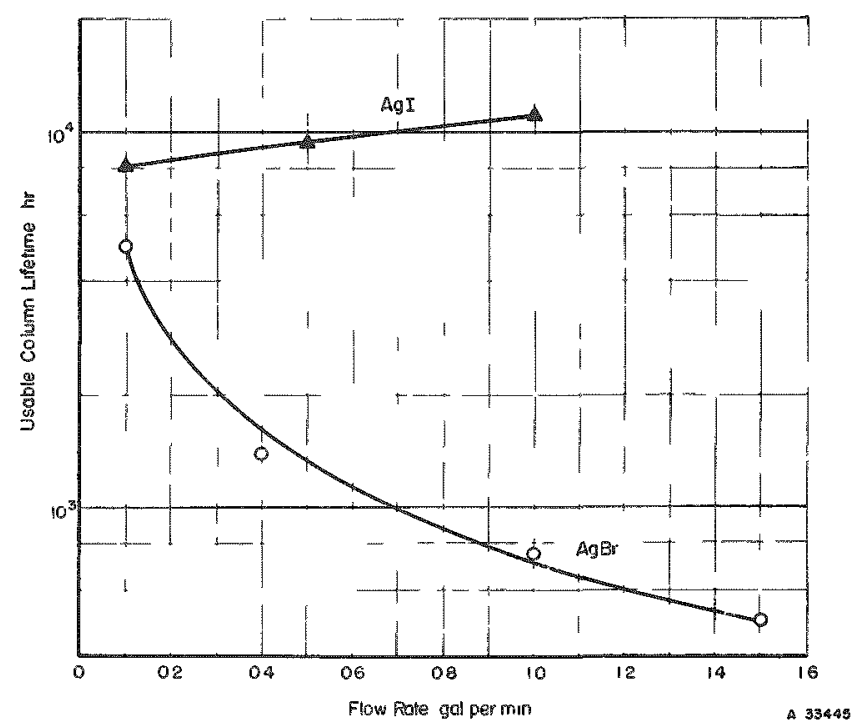

FIGURE 4. USABLE EXCHANGE-COLUMN LIFETIME IN 180 F WATER AS A FUNCTION OF FLOW RATE

The lifetime estimates shown are for $50-\mathrm{g}$ columns 1 in. high by 1 in. in diameter. 


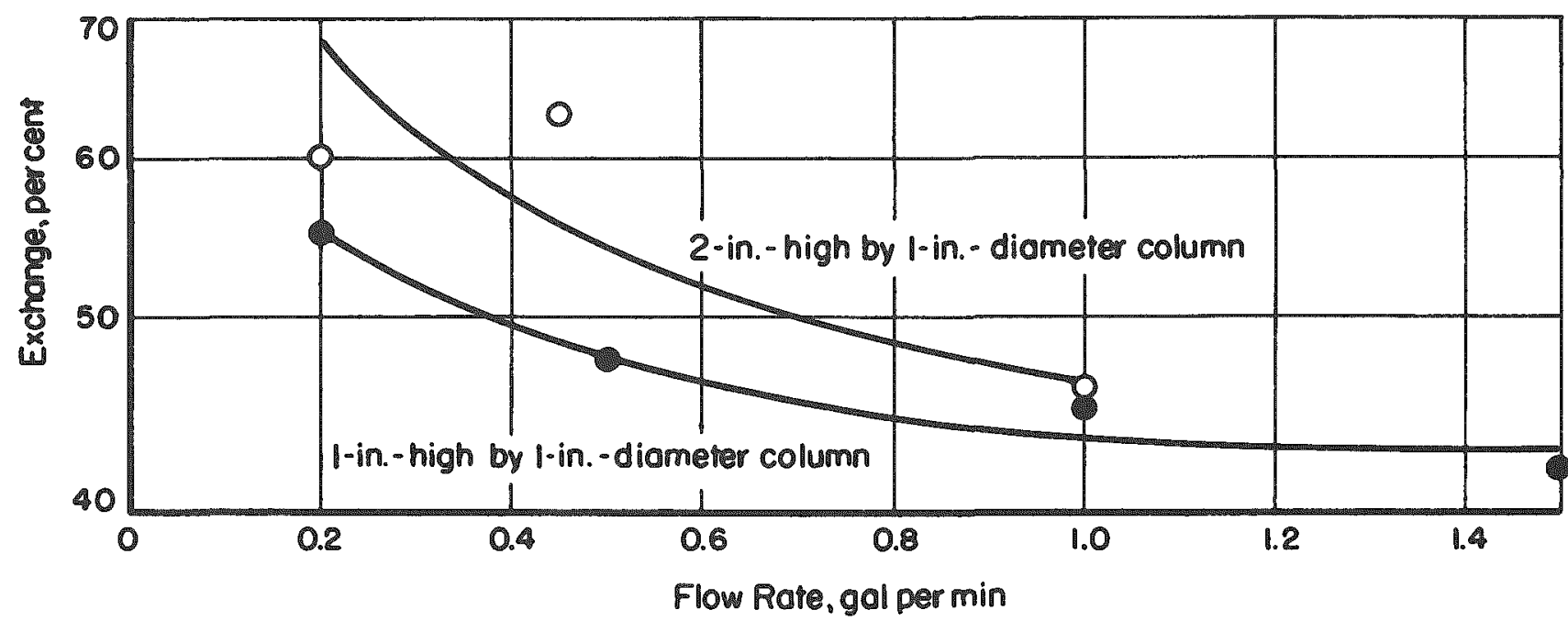

FIGURE 5. EXCHANGE BETWEEN SILVER BROMIDE AND IODINE-131 IN 180 F WATER AS A IUNCTION OF FLOW RATE

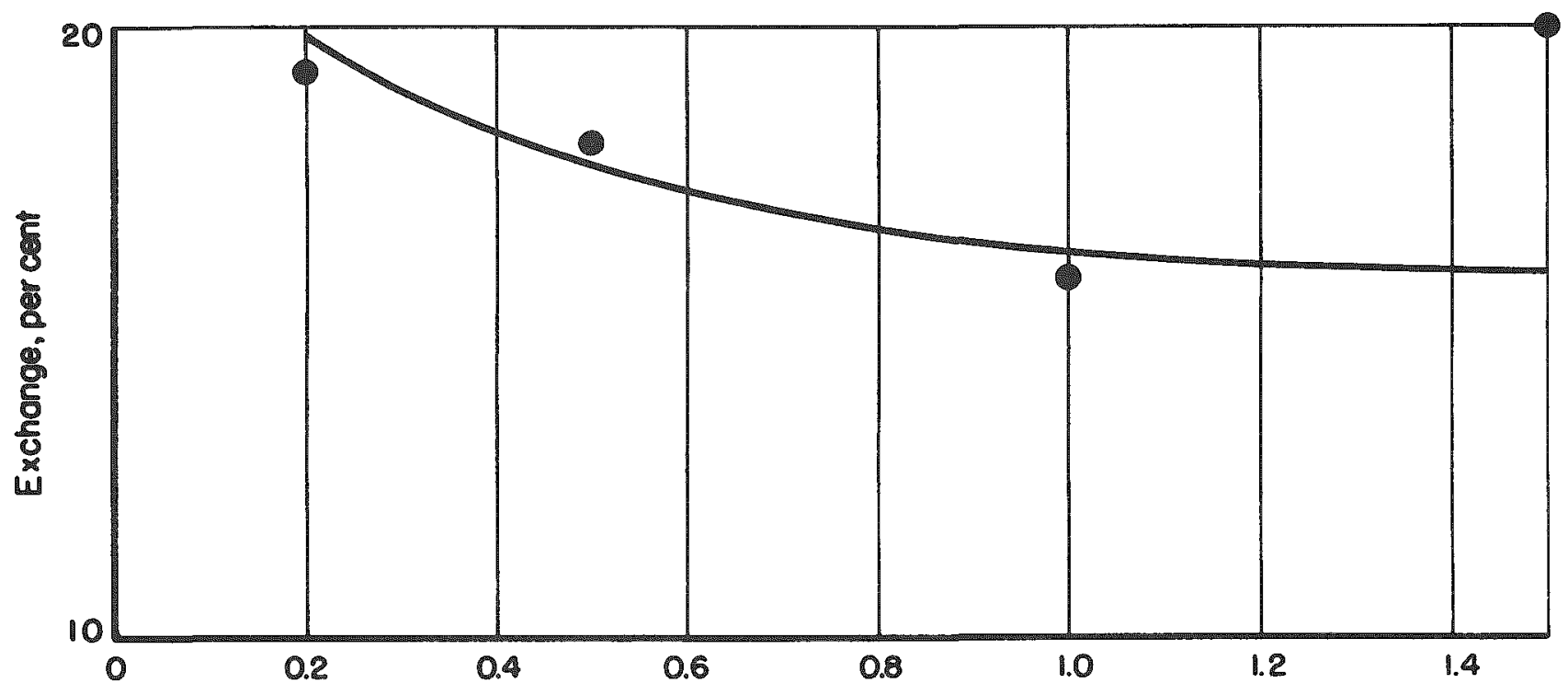

Flow Rate, gal permin

FIGURE 6. EXCHANGE BETWEEN SIL VER BROMIDE AND BROMINE-82 IN 180 F WATER AS A FUNCTION OF FLOW RATE

These data were obtained with a column 1 in. high by $\mathbb{l}$ in. in diameter. 
Rate of Removal of Bromine-82 and Iodine-131

From Silver Bromide Columns

In order to obtain information on the equilibrium concentrations of bromine and iodine isotopes on AgBr columns, it was necessary to determine the "wash-off" rate of these isotopes following their removal from the coolant. These experiments were conducted by passing bromine-82 and iodine-131 through $50-\mathrm{g}$ columns of minus 16 plus $50-$ mesh fused silver bromide and then following the subsequent removal of these isotopes by monitoring the column with a gamma scintillation probe. The rate of removal of bromine -82 was determined at 75 and $180 F$ and that of iodine-131 was determined at $180 \mathrm{~F}$. The flow rate through the silver bromide columns was $0.5 \mathrm{gal}$ per min.

The rates of removal of bromine -82 and iodine- 131 are presented graphically in Figure 7. Because of the rapid rate of removal of bromine and the relatively low exchange at $180 \mathrm{~F}$, the equilibrium concentration of bromine on the column will be lower than that of iodine, and the time required to reach equilibrium will be less for bromine isotopes. In the section devoted to the calculation of equilibrium concentrations of halide fission products on silver halide columns, these wash-off rates have been taken into consideration.

Fission-Product-Decontamination Studies

The retention of gross fission products was studied by passing $5-\mu c$ aliquots of fission-product solution through $50-\mathrm{g}$ ( 1 in. high by 1 in. in diameter) and $100-\mathrm{g}(2 \mathrm{in}$. high by 1 in. in diameter) columns at flow rates ranging from 0.2 to 1.5 gal per min. A mixed anion-cation exchange resin bed was used to collect the fission products after one pass through the AgBr column. Temperature during the runs was maintained at $180 \mathrm{~F}$. The quantity of fission products retained was determined by radioassaying the AgBr. The percentage of fission products retained was calculated by dividing the quantity of fission products retained (in $\mathrm{cpm}$ ) by the quantity of fission products passed through the column (in cpm).

The retention of fission products by $\mathrm{AgBr}$ is given in Table 2. The decontamination factor is the ratio of per cent iodine-131 retained to the per cent fission products retained. Decontamination factors under the conditions studied varied from 10 to 26 .

Several methods were considered for reducing gross fission-product contamination of silver halide columns, since better decontamination would result in a higher signalto-background ratio for gross gamma monitoring. Fission products were passed through columns of glass wool and silica gel prior to passing them through an AgBr column. While these materials adsorbed a large fraction of the fission products, the fissionproduct retention by the AgBr was not decreased. 


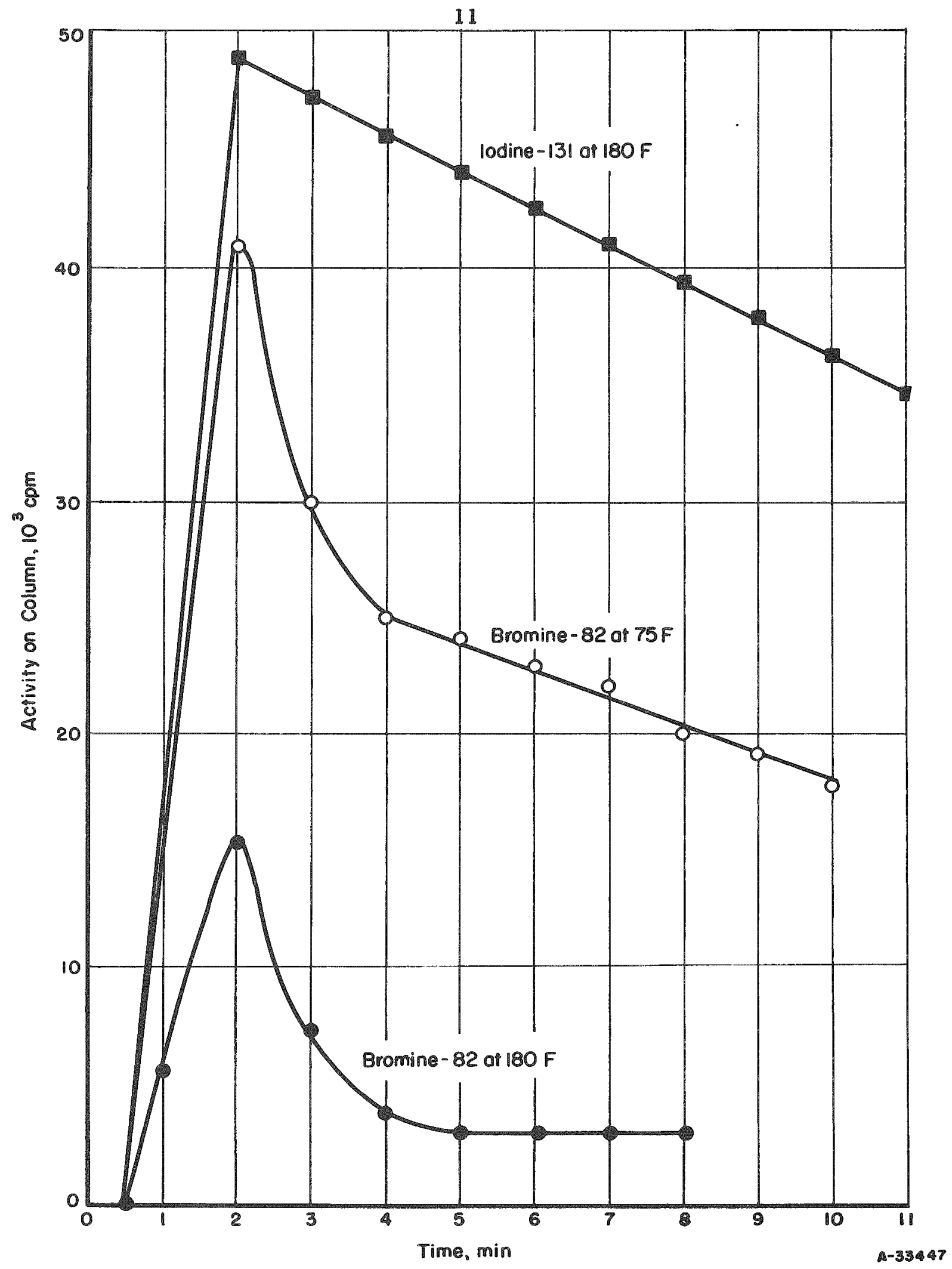

FIGURE 7. RATE OF REMOVAL OF IODINE-131 AND BROMINE-82 FROM SILVER BROMIDE COLUMNS 
TABLE 2. FISSION-PRODUCT RETENTION AND DECONTAMINATION FACTORS AS A FUNCTION OF FLOW RATE FOR 1 BY 1 AND 2 BY 1-IN. SILVER BROMIDE COLUMNS

\begin{tabular}{|c|c|c|c|c|}
\hline Column Size & $\begin{array}{l}\text { Flow Rate, } \\
\text { gal per min }\end{array}$ & $\begin{array}{c}\text { Fis sion Products } \\
\text { Retained, } \\
\text { per cent }\end{array}$ & $\begin{array}{l}\text { Iodine-131 } \\
\text { Retained, } \\
\text { per cent }\end{array}$ & $\begin{array}{c}\text { Decontamination } \\
\text { Factor(a), } \\
\text { per cent }\end{array}$ \\
\hline \multirow{4}{*}{$\begin{array}{l}1 \text { in. high by } 1 \text { in. } \\
\text { in diameter }\end{array}$} & 0.2 & 4.8 & 55 & 12 \\
\hline & 0.5 & 2.5 & 47 & 19 \\
\hline & 1.0 & 2.8 & 45 & 16 \\
\hline & 1.5 & 4.5 & 44 & 10 \\
\hline \multirow{3}{*}{$\begin{array}{l}2 \text { in. high by } 1 \text { in. } \\
\text { in diameter }\end{array}$} & 0.2 & 2.3 & 60 & 26 \\
\hline & 0.5 & 4.1 & 64 & 16 \\
\hline & 1.0 & 3.3 & 45 & 14 \\
\hline
\end{tabular}

(a) The decontamination factor is the ratio of the percentage of lodine-131 retained to the percentage of fission products retained.

In other experiments, ethylenediaminetetraacetic acid (EDTA) was mixed with the fission-product solutions in an attempt to complex the fission products and prevent their adsorption on the AgBr column. The fission products were passed through a column of EDTA pills prior to being contacted with the AgBr column. This technique reduced the fission-product contamination on the AgBr column by one-half, but it is likely that an even greater reduction in fission-product retention is necessary. Other experiments directed toward improving fission-product decontamination included saturation of the surface of the AgBr with cerium, lanthanium, and zirconium carriers before contacting the AgBr with fission products and the addition of these three carriers to fission products prior to passing them through an AgBr column. Both methods were found to lower fission-product retention only by a factor of two. The fact that carrier addition did not significantly reduce the fission-product absorption on the AgBr would indicate that the fission products either were in different oxidation states than the carrier or else the retained fission products were absorbed on particulate matter and did not exchange with the carrier solutions.

The greatest change in fission-product retention was observed when the pH of the fission-product solutions was lowered before passing them through AgBr columns. Only 0.18 per cent of the fission products passed through an AgBr column was retained when the fission products were in $\sim 0.3 \mathrm{~N} \mathrm{HNO}_{3}$. Also, fission products were easily washed from AgBr columns by rinsing the columns with $6 \mathrm{~N} \mathrm{HNO}_{3}$. Only 0.05 per cent of the fission products originally passed through a AgBr column was retained after a wash with $6 \mathrm{NHNO}_{3}$. 
Calculation of Halide Buildup on

Silver Bromide Columns

The information presented in the previous sections shows the halide and gross fission-product retention on solid silver halide as a function of various column operating conditions. It is now of interest to determine the combined effect of halide retention, decay and washing off on the buildup of halide fission products on AgBr columns.

The rate at which halide fission products are removed from the coolant and deposited on the silver bromide column is given by the equation:

$$
\frac{\mathrm{dN}}{\mathrm{dt}}=\mathrm{k}_{1} I_{0}
$$

where

$$
\begin{aligned}
& I_{0}=\text { the number of radioactive halide atoms passing a given point } \\
& \text { in the loop per second } \\
& \mathbb{N}=\text { the number of radioactive halide atoms on the resin at } \\
& \text { any time } \\
& k_{1}=\text { the fraction of solution radioactive atoms picked up by the } \\
& \text { resin per second. }
\end{aligned}
$$

The bromine-82 wash-off curves show that the removal of bromine, and presumably iodine, may be satisfactorily represented by an equation of the form:

$$
\frac{d N}{d t}=-k_{2} N
$$

where $k_{2}=\frac{0.693}{T_{1 / 2}}$ and $T_{1 / 2}$ is the time required to wash one-half of the radioactive bromide from the silver bromide. In addition to washing off, radioactive decay of the bromine occurs so that the total loss of radioactive bromine from the silver bromide is given by:

$$
\frac{d N}{d t}=-\left(k_{2}+\lambda\right) N
$$

where $\lambda$ is the decay constant of the bromine. The total rate of increase or decrease of bromine on the column is given by the sum of Equations (1) and (3):

$$
\frac{d N}{d t}=k_{1} I_{0}-\left(k_{2}+\lambda\right) N
$$

Equation (4) may be integrated to yield an expression for the number of radioactive bromine atoms on the column at any time t:

$$
N=\frac{k_{1} I_{0}}{k_{2}+\lambda}\left[1-e^{-\left(k_{2}+\lambda\right) t_{1}}\right],
$$


and this equation may in turn be multiplied by $\lambda$ to yield an expression for the disintegration rate of the bromine on the column:

$$
\frac{d N}{d t}=\frac{\lambda k_{1} I_{0}}{k_{2}+\lambda}\left[1-e^{-\left(k_{2}+\lambda\right) t_{1}}\right] \text {. }
$$

Using the values of $k_{1}$ and $k_{2}$ obtained experimentally for bromine and iodine and using values of $\lambda$ tabulated in the literature, the disintegration rates at various buildup times were calculated for all the halide fission products. In this calculation, it was assumed that all the halide fission products were completely equilibrated at a thermal flux of $10^{14} \mathrm{nv}$. A uranium leak rate of $10 \mathrm{mg}$ per min into a coolant flow of 200 gal per min was assumed. Gamma-ray and delayed-neutron backgrounds were estimated by assuming that nitrogen-16 and nitrogen-17, derived from oxygen-16 and oxygen-17 in the coolant, were the chief contributors to the background. If these isotopes were completely equilibrated at a flux of $10^{13} \mathrm{nv}$, an estimated background of 400 neutrons per sec per $\mathrm{cm}^{3}$ of coolant and $10^{6}$ high-energy gamma rays per sec per $\mathrm{cm}^{3}$ of coolant would be obtained for coolant just leaving the reactor. The background from fission-product contamination of the AgBr was not considered, since the magnitude of this effect must be determined experimentally in actual reactor operation. The buildup of halide gross gamma activity on a AgBr column with time is shown in Figure 8. It appears that a holdup time of approximately $20 \mathrm{sec}$ would be necessary before the halide gamma activity exceeded background.

Figures 9 and 10 show the buildup of halide gamma emitters above 2 and $3.5 \mathrm{Mev}$, respectively. In both cases the activity from the halides is considerably lower than the estimated background from nitrogen-16.

The curve in Figure 11 shows the buildup of delayed-neutron-emitting isotopes of bromine and iodine on a AgBr column. It appears that a satisfactory signal-tobackground ratio can be obtained after a 10-sec holdup time and a 10-sec buildup time. After a $20 \mathrm{msec}$ holdup time the signal-to-background ratio increases to about 10 due to the decay of 4.14-sec-nitrogen-17, which is the major contributor to the neutron background.

\section{DISCUSSION AND CONCLUSIONS}

The results of the investigation indicate that it is possible to construct an effective leak-detection system based on the isotopic-exchange principle.

The optimum exchange material for use in the system would be either silver bromide or silver iodide, since the solubility of silver chloride is undesirably high. Investigations prior to this program indicated that silver bromide had the apparent advantage of retaining both bromine and iodine isotopes at room temperature, while silver iodide retained only iodine isotopes. However, in view of the low AgBr-bromine isotope exchange at $180 \mathrm{~F}$ and the rapid washing off of the exchanged bromine isotopes, the bromine contribution to the total separated halide activity will be relatively small in the case of both gross gamma and delayed-neutron detection. The major fraction ( 90 per cent) 


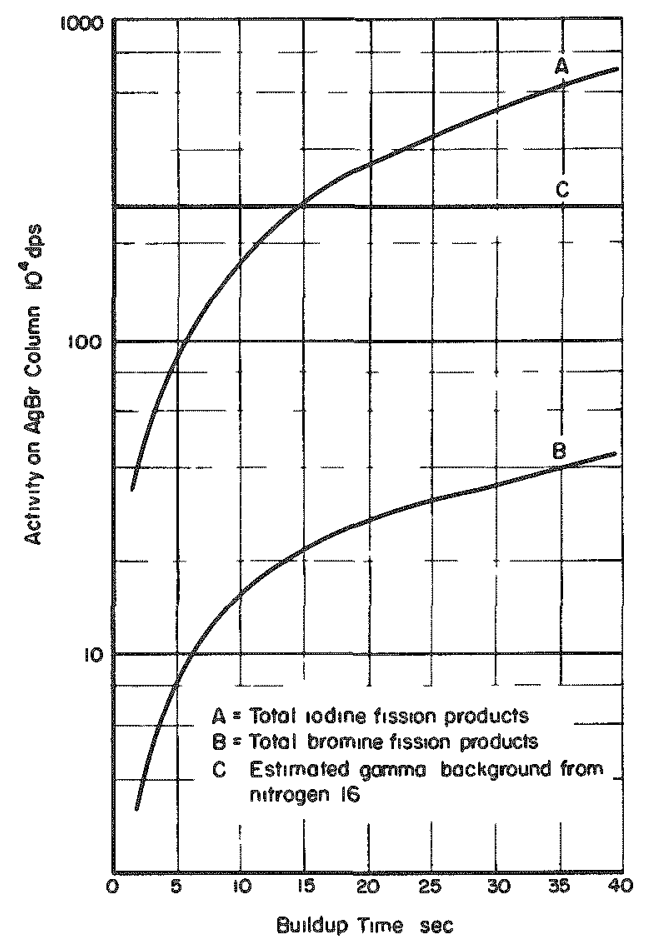

FIGURE 8. BUILDUP OF HALIDE FLSSION PRODUCTS ON SILVER BROMIDE COLUMNS AT 180 F

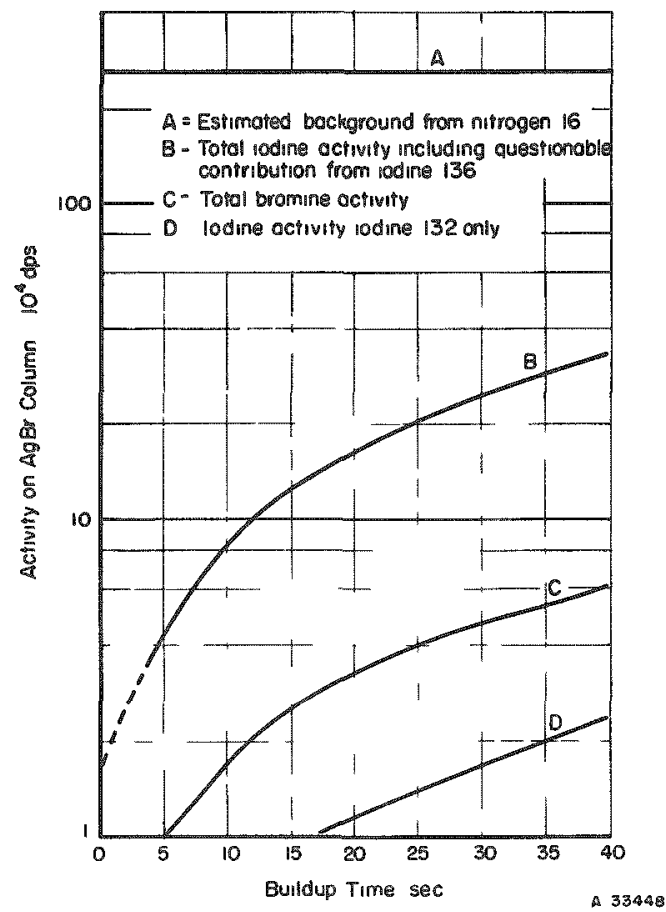

FIGURE 9. BUILDUP OF HALIDE FISSION PRODUCTS EMITTING HIGH-ENERGY GAMMA RAYS (P2 MEV) ON SILVER BROMIDE COLUMNS AT $180 \mathrm{~F}$ 


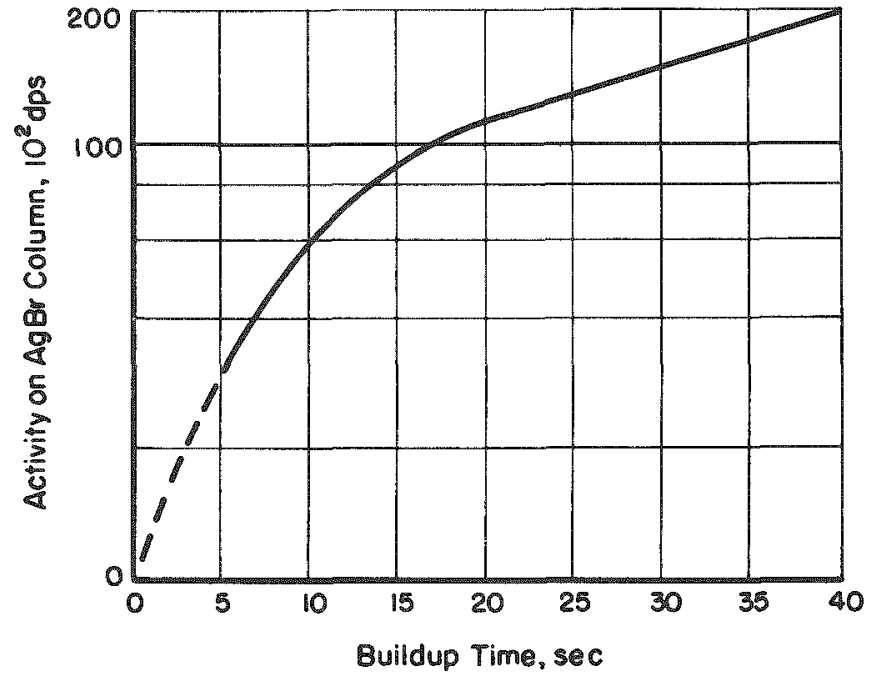

FIGURE 10. BUILDUP OF HALIDE FISSION PRODUCTS EMITTING HIGH-ENERGY GAMMA RAYS (>3.5 MEV) ON SILVER BROMIDE COLUMNS AT 180 F

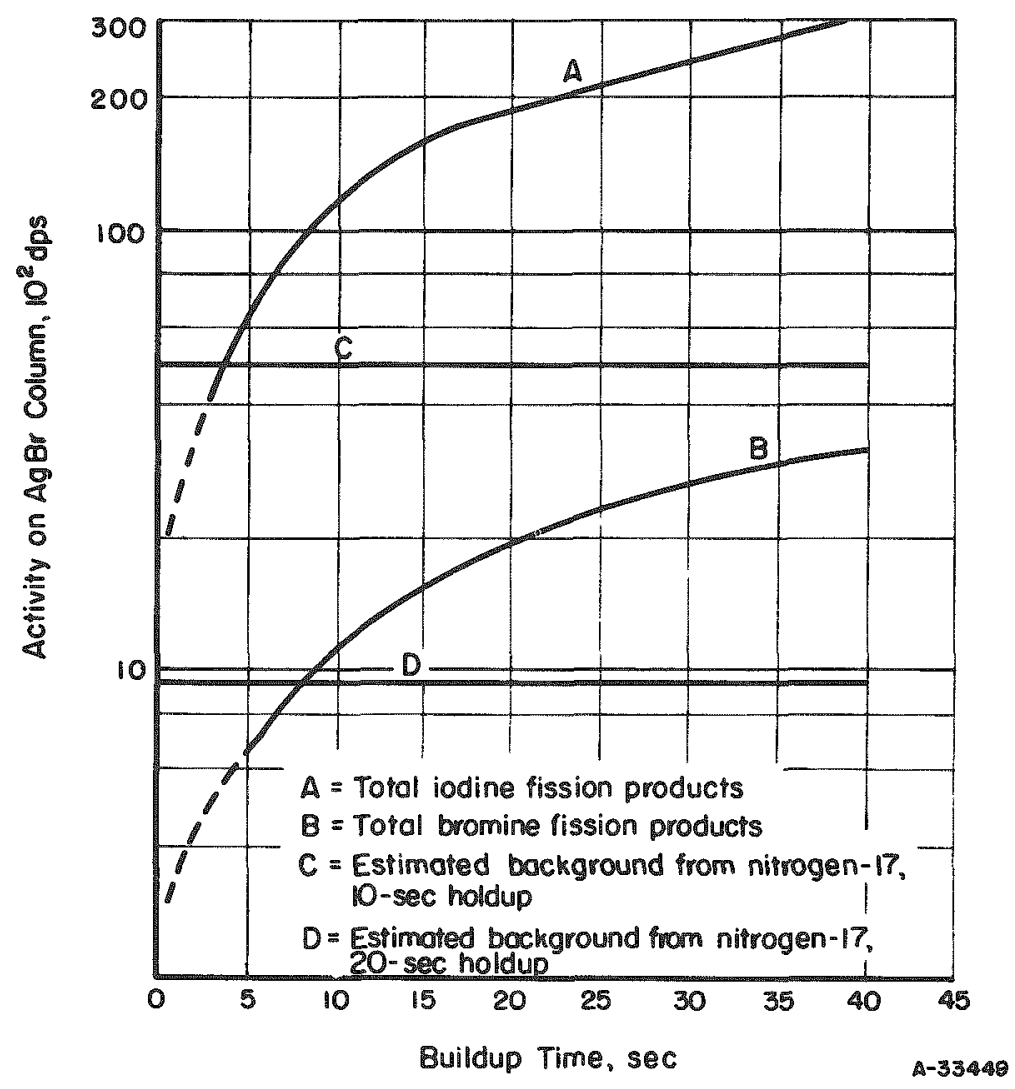

FIGURE 11. BUILDUP OF DELAYED-NEUTRON EMITTERS ON SILVER BROMIDE COLUMNS AT $180 \mathrm{~F}$ 
of the halide activity will be contributed by iodine isotopes. Consequently silver iodide may be a more satisfactory exchange material than silver bromide since, at a flow rate of 0.5 gal per min, the expected lifetime of an AgI column is about $9000 \mathrm{hr}$ compared with 1300 hr for AgBr.

Flow rate and column size apparently have only a slight effect on exchange and fission-product retention. Column sizes of $1 \mathrm{in}$. high by $1 \mathrm{in}$. in diameter and 2 in. high by 1 in. in diameter and flow rates ranging from 0.2 to 1.5 gal per min varied AgBriodine-131 exchange from 43 to 63 per cent. Fission-product retention under similar column-size and flow conditions varied 2.5 to 4.8 per cent. The decontamination factors ranged from 10 to 26 .

It appears that a system in which concentration of halide fission products by isotopic exchange and delayed-neutron monitoring of the separated halides were performed would possess favorable properties as a leak-detection device. This system should give high signal-to-background ratios for detecting a leak and should not be sensitive to buildup of gross fission products on the AgX column. On the other hand, the gross gamma monitoring system would be complicated by increased background due to fissionproduct buildup. The magnitude of fission-product buildup cannot be accurately determined from laboratory experiments, but can only be determined by in-pile-loop experiments.

\section{REFERENCES}

(1) Millar, C. H., Sargent, B. W., and Horsman, J. C., J. Nuclear Sci. Eng., 2, 363 (1957).

(2) Palladino, W. J., "PWR Fuel Element Failure Detection System", WAPD-PWR-RD229 (May 22, 1956).

(3) Dewes, R. A., "Location of Multiple Reactor Fuel Element Failures by Delayed Neutron Sampling Methods", AECU-3937 (November 25, 1958).

(4) Gordon, C. M., and Hoover, J. I., "Burst-Slug Cerenkou Detector", Nucleonics, $15(1), 91(1957)$.

(5) Heath, R. L., "Fission Product Monitoring in Reactor Coolant Streams", IDO$16213(1956)$.

(6) Frank, P. W., and Vogel, K. H., "Theory of Failed Fuel Element Location and Detection", WAPD-BT-3 (1956).

(7) Frank, P. W. "Calculation of Fission Product Activity in PWR From a Seed Plate Failure", WAPD-TM-83 (1957).

(8) Unpublished work at BMI.

JEH/TSE/DNS: pa 